\title{
Impact of Product-Service Systems on the Energy Efficiency of Machine Tools
}

\author{
Gülsüm Mert ${ }^{1, a^{*}}$, Jan C. Aurich ${ }^{1, b}$ \\ ${ }^{1}$ Institute for Manufacturing Technology and Production Systems, University of Kaiserslautern, \\ Germany \\ aguelsuem.mert@mv.uni-kl.de \\ bublications.fbk@mv.uni-kl.de \\ * Corresponding author
}

Keywords: Product-Service Systems, energy efficiency, machine tools

\begin{abstract}
Many machine tool manufacturers offer services to support their customers over the lifetime of a product. This kind of integration of products and services is called Product-Service Systems (PSS). PSS offer advantages for the customers as well as for PSS providers because they fulfill customers' requirements and ensure a long and successful customer relationship. Since sustainability is getting more and more important and customers are interested in sustainable solutions, PSS providers need to improve the environmental impact of their products and services continuously. Under this aspect, an approach is necessary that identifies the ecological potential of services for machine tools. In this paper, an approach to analyze the impact of Product-Service Systems on the energy efficiency of machine tools is presented.
\end{abstract}

\section{Introduction}

Energy is an important metric of environmental impact and manufacturing efficiency [1] and is one of the main production resources. Until recently, energy as a cost factor was a low priority for many industrial enterprises. Energy costs have been a high proportion of the budget, around $40 \%$ of the overall costs of production, for energy intensive industries such as cement, paper, or steel manufacturers [2]. Therefore, the manufacturing industry cannot operate without proper and save energy supply [2].

Optimizing energy efficiency of machine tools is a significant economic objective as well as an important environmental objective. It is estimated that 3.5 million installed machine tools in the EU27 demand 200-300 TWh per annum [3]. By optimizing the energy efficiency of machine tools, reducing the energy demand in the production in particular mechanical engineering and automotive industry is possible. According to [4] by implementing technical measures, e.g. optimizing the cooling units or hydraulic system, the energy efficiency of a machine tool can be increased dramatically. In addition to technical measures, there are organizational measures which focus on the operating mode and also help to increase the energy efficiency of a machine tool. Service related measured do also exist and can be assigned to technical and organizational measures. In the literature it is not identified whether service related measures influence the energy efficiency of machine tools. There is a research gap concerning the dependencies between services and machine tools' efficiency. In this paper, the research question is focused on measures by life cycle oriented services for machine tools. An approach will be presented to analyze the impact of services on the energy efficiency of machine tools. The approach has four steps for the analysis. The first step is to figure out life cycle oriented services for machine tools. In the second step the energy efficiency of machine tools will be assessed. In the last two steps, services with an impact on the energy efficiency of machine tools will be identified and evaluated. 


\section{Related work about energy efficiency of machine tools}

Machine tool manufacturers are interested in improving the efficiency of their products. There are numerous technical measures to improve the energy efficiency of machine tools. In the literature, is also possible to find a lot of results and suggested measures. In Neugebauer et al the product development process is focused to consider energy relevant aspects. They regard the energy efficiency of a machine tool when defining the product geometry or defining the manufacturing processes [5]. However, it is also possible to optimize the energy efficiency of a machine tool after the product development. Herefore, the process can be improved by using shorter cycle times and avoiding energy consumption for a high pressure of the cooling lubricant system [6].

Another option is using more energy efficient components for the motor and pumps of the cooling lubricant system, for the motor of the suction, for the thermal management of electrical enclosures and for the machine cooling system [7]. Especially considering efficient components for the cooling units is important since the cooling units can save one third of the total energy demand of a machine tool [7]. More details about technical measures for machine tools can be found in the paper [8].

There are many technical measures for improving the energy efficiency of machine tools and these need to be considered when offering services during the usage phase a machine tool. However, in the literature does not exist an approach which considers the impacts of services on the energy efficiency of a machine tool or on the technical measures.

\section{State-of-the-art about Product-Service Systems (PSS)}

Product-Service Systems (PSS) consist of a technical product which is supported and enhanced over its lifetime by different services [9]. PSS are also defined as a system of products and services which are able to fulfill specific customer requirements [10]. By offering life cycle oriented services, it is proposed to extend the lifetime of the product [11]. To realize PSS the capital goods manufacturer (PSS-provider) has to collaborate with each partner of his extended value-added network. The extended value-added network consists of the development network, manufacturing network and service-network. When the process of selling a product and service is connected, the partners of the extended value-added network can optimize not only their own business but the entire value chain. Depending on their goals PSS synergies can be used in profit, competitiveness and environmental benefits [10]. To analyze and control the environmental benefits of PSS, it is necessary to look at its elements in more detail. Therefore, in figure 1 PSS is presented as a system. To fulfill a defined functionality of PSS, the subsystems and PSS elements of the system need to interact. PSS can be divided into three subsystems: product, customer and service network. The product consists of several components. The subsystem customer includes all PSS elements which are necessary to produce one part, e.g. the operator, repair shop, auxiliaries like oil or cooling lubricants and other resources. The service network includes the service technicians, spare parts, tools and other resources to realize the service for the customer [12]. 


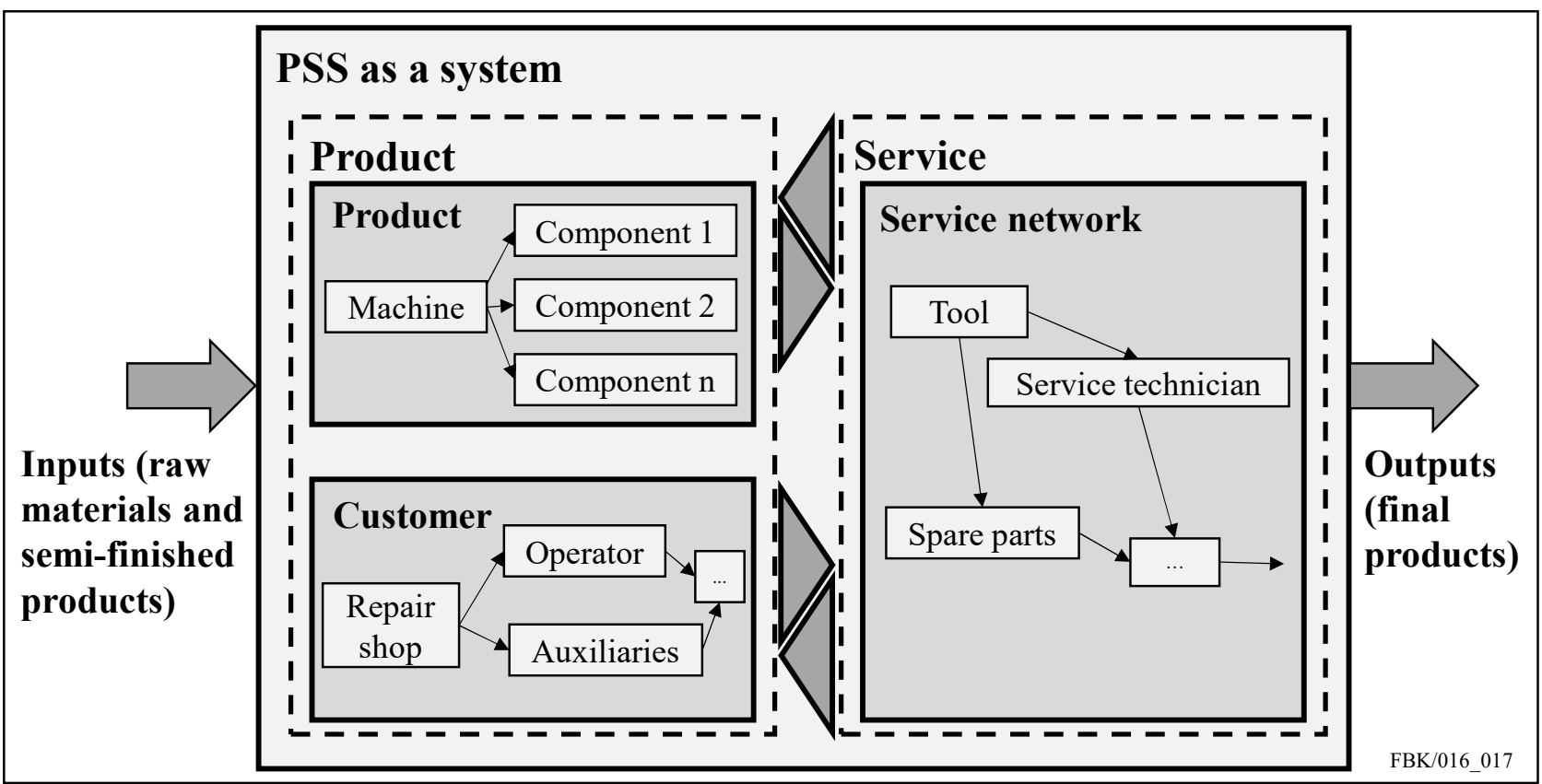

Figure 1: Product-Service Systems from a system point of view [12]

PSS include human resources and services that are mainly driven by the service technician, so the operator and the service technician have to be considered when evaluating the environmental benefit of PSS. The methodology of [1] is taken to analyze human resources. In this paper, it is explained how to estimate the energy demand of an hour of industrial labor. Usually environmental analyses do not consider labor although the cost of labor are significant in economic analyses. Assessing and evaluating the energy use of labor is an opportunity to close the gap between analyses which prioritize environment and ones which focus on economics [1].

The energy use per worker-hour can be compared to the power consumption of an automated milling machine and can be taken as a decision making application. It was estimated that one operator of a milling machine is responsible for $2.9 \mathrm{kWh}$ and the machine itself for $0.7 \mathrm{kWh}$ [1]. Although the automated machine consumes four times more energy per hour than a manual milling machine, if a worker can operate several machines at the same time than the automated milling machine is more reasonable in terms of energy use.

Without quantifying the energy use of labor, the environmental impacts of labor intensive processes like maintenance, repair and recycling can be underestimated [1]. For this reason, the following approach includes the cost of labor when analyzing the impact of services on the energy efficiency of machine tools.

\section{Approach for analyzing the impact of PSS on the energy efficiency of machine tools}

The following approach has been developed to analyze the influence and interdependencies between services and machine tools over the entire lifetime of a machine tool. The research question is how services affect the energy efficiency of a machine tool. The approach consists of four steps. The first step is the analysis of the life cycle of a machine tool. In the second step, the energy efficiency of the machine tool needs to be investigated to have an actual value. In the third step, the impact of services on the energy efficiency of a machine tool needs to be analyzed. For this step, it is necessary to identify the interdependencies between the PSS elements and then to classify influencing factors according to impact on the efficiency of a machine tool. In the final step, the results are calculated by a software tool to present the influence of PSS on the energy efficiency of the machine tool. 


\subsection{Step 1: Analysis of life cycle oriented services for machine tool}

In the first step, life cycle oriented services for machine tools are analyzed in order to classify services for each life cycle phase and identify any service gaps. Hereby, the life cycle is regarded from the perspective of the customer. It starts with the procurement of the machine tool and ends with the end of life. During the lifetime different services will be provided by the manufacturer which affect the energy efficiency of a machine tool, e.g. process consulting to avoid oversized machine components, preventive maintenance to avoid damages on other components or retrofitting of a control system to extend the lifetime of the machine tool.

\subsection{Step 2: Assessment of the energy efficiency of a machine tool}

The second step of the approach is the assessment of the energy which the machine tool needs during the usage phase compared to the amount of produced parts in this time. This step is necessary to get a comparative value for later on and to estimate a reference value. The reference value or functional unit is defined as the energy demand per produced part. The energy input includes services which are necessary to produce the parts. So the system boundaries of the energy analysis include the energy which is necessary for the transportation of the machine tool to and implementation of it at the customer, the test phase, the usage, the maintenance as well as the energy which is necessary for the disposal of the components at the end of life. For each service process, the costs of labor, operating materials and work equipment have to be regarded. All production factors have to be converted due to the functional unit. Since the service realization mainly depends on the service technician, the cost of labor and energy demand of a worker is included. The identification of the inputs of each process step for the service realization can be done as it is presented in figure 2. After identifying the production factors, their unit and the formula, impact factors of each production factor need to be investigated. The impact factors are necessary to find out measures and evaluate the services to improve the energy efficiency of the machine tool in the next step of the approach.

\begin{tabular}{|l|l|l|l|l|l|l|}
\hline & Process step & Production factors & Unit & Calculation & Impact factor & Measures \\
\hline $\begin{array}{l}\text { 1: Arrival of } \\
\text { service } \\
\text { technician }\end{array}$ & - Car or plane & $\mathrm{L} / \mathrm{km}$ & $\begin{array}{l}\text { Distance * } \\
\text { consumption }\end{array}$ & $\begin{array}{l}\text { Consumption of } \\
\text { transportation } \\
\text { resources }\end{array}$ & $\begin{array}{l}\text { Travel with } \\
\text { train }\end{array}$ \\
\hline
\end{tabular}

Figure 2: Process steps of a service realization

\subsection{Step 3: Identification of services for increasing the energy efficiency of a machine tool}

The third step is the identification of life cycle oriented services that have an impact on the energy efficiency of a machine tool. In [13], different influencing factors to the energy efficiency of machine tools are presented. These factors include the machine itself, the environment and its technology. However, in this approach the factors are classified according to the product, the service, the extended value chain and the business model. Product related factors, for instance, are the factors of the process e.g. process time, parameters, power class and material. Service oriented factors are related to the human factor. Service oriented factors include the knowledge and education of the operator, duration of the service and frequency of maintenance. The interdependencies between these factors are evaluated from a range 0 to 3 and the factor will be rated higher according to the strength of the factor's influence. The results are drawn in a matrix to present the strength and the controllability of each influencing factor. The controllability is important to consider because if 
it is not easy to regulate measures cannot be derived to improve the energy efficiency of the machine tool. In figure 3 the results are shown in a matrix. For instance the amount of worker training (factor number 3) has a low impact on the energy efficiency but a high influence on the simplification of the usability because a training improves the knowledge of the operator which will simplify the product use for him. The factor training has a low influence on the service frequency and the cumulated strength of impact is in this example rated with 5. The controllability is rated with 4 which means it is an impact factor that can be controlled medium heavily. In the diagram next to the matrix this factor is placed in the middle area. By classifying the influencing factors it is easier to identify critical, active, passive or idle impact factors. The critical factors are good to control and have a high impact, the active ones also have a high impact but are hardly to control. The passive factors have low impacts but are controllable and the idle ones are factors which can be ignored since they do not have an impact and are difficult to control.

The results of the classification can differ depending on the person who evaluates the influencing factors and has the disadvantage of showing subjective results. However, it is a method which offers the possibility to evaluate factors and rank them due to their strength of impact and controllability.

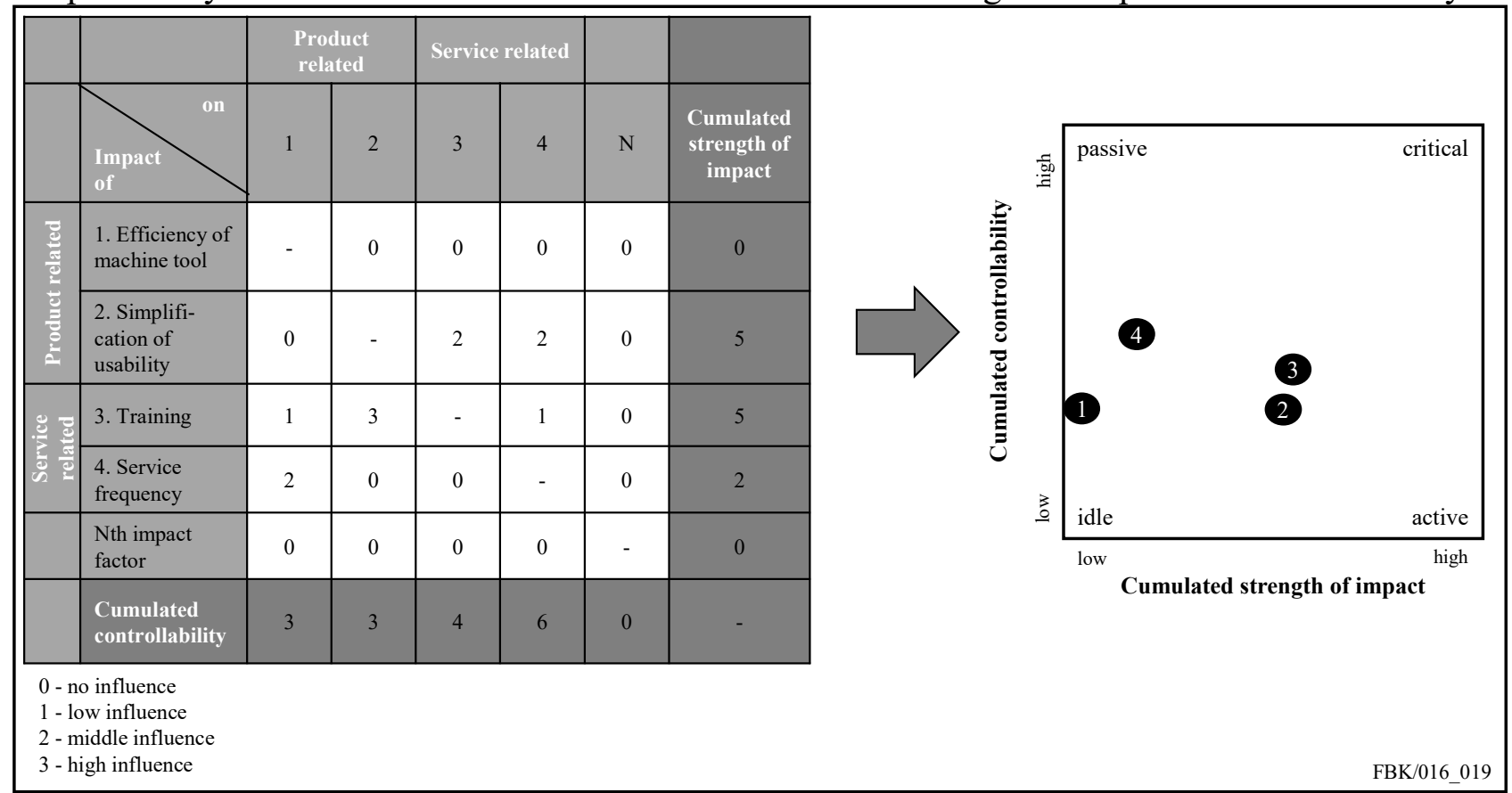

Figure 3: Classification of service related impact factors on the energy efficiency of machine tools

\subsection{Step 4: Evaluation of the influence of PSS}

In the last step, the impacts of life cycle oriented services will be presents. An energy card for PSS is developed to present customers the ecological benefit of life cycle oriented services (see figure 4). The energy card presents an overview of the energy demand of the machine tool and consists of three levels. The first level is for the total energy demand and costs of the customized PSS. On the second level the customer can see the different services with the process steps of each service. For each process step the rated impact factors, measures, actual and target energy efficiency as well as the savings need to be listed. The energy efficiency and demand of the product is on the third level and is regarded for different process conditions, e.g. hours of stand-by, full load or off-mode. The customer can measure the energy demand and efficiency of his PSS and set up control levers depending on its own targets. 


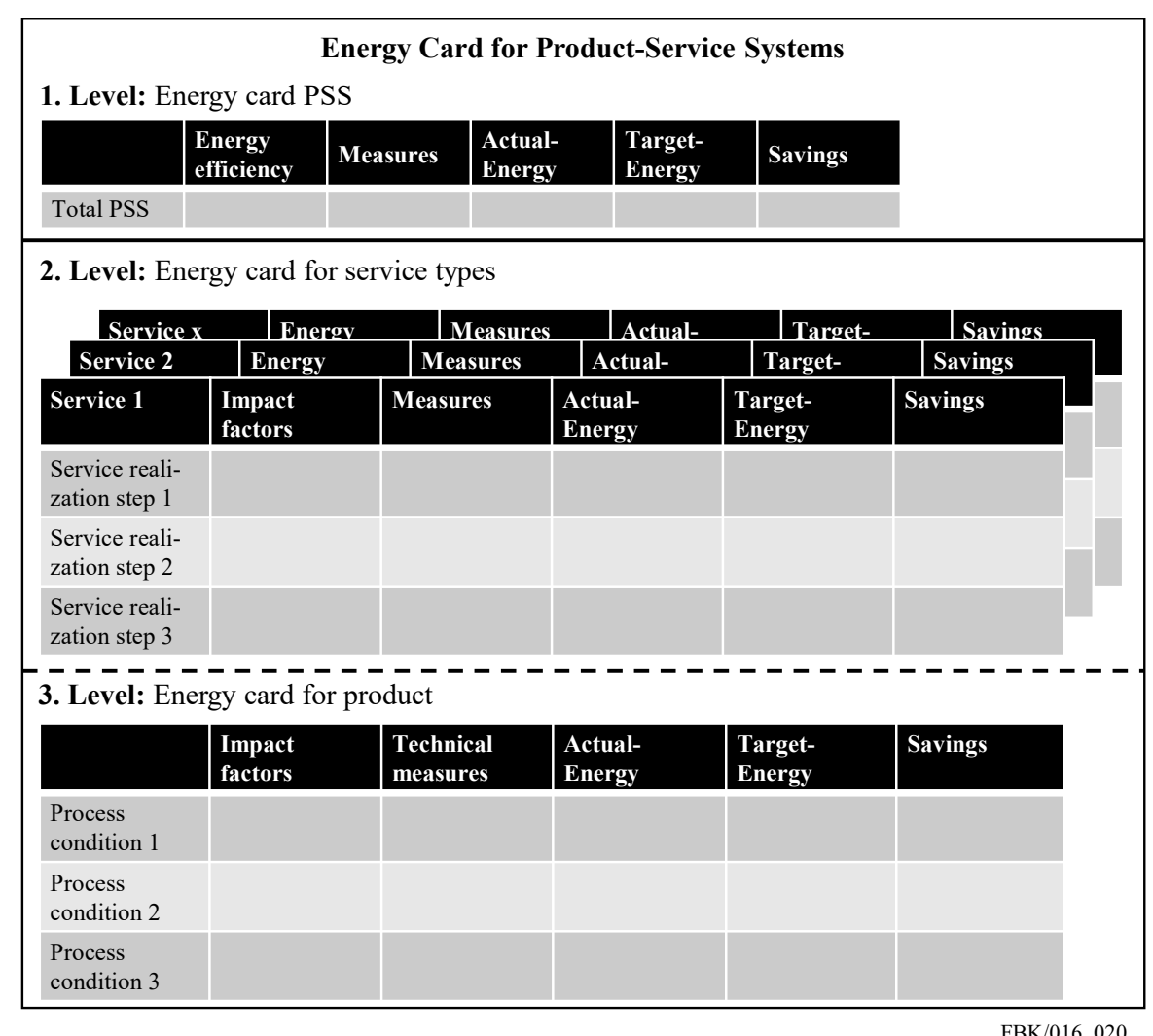

Figure 4: Energy Card for Product-Service Systems

\section{Summary}

The environmental impact of PSS is a complex topic to evaluate. In particular, the sustainability of a service realization, which is usually immaterial and mainly depends on the human factor, is very complicated to assess, compare and control. In this paper, an approach is presented with four steps to analyze the impacts of PSS on the energy efficiency of a machine tool. For considering the human factor in the approach and calculating the energy demand of a worker, the research of [1] is taken into consideration. The first step of the approach clarifies the identification of life cycle oriented services for machine tools. In the second step, it is explained that the service realization process needs to be analyzed in detail to determine influencing factors. The third step presents a method to evaluate the determined influencing factors and classify the most critical ones due to their strength of impact on other factors and on the energy efficiency of the machine tool. In the last step, an overview of the energy card is presented.

In the future, the approach will be validated on a grinding machine that is supported by the services retrofit of the spindle and control system as well as maintenance. For the validation, an Excel-based demonstrator will present a scenario with a grinding machine that is maintained and replaced after 20 years of lifetime by a new machine versus a grinding machine that will be continuously maintained and will get a retrofit after 20 years. The energy demand of the grinding machines and the amount of produced parts of both machines will be determined. The production factors of the service realization will be regarded as well. For this, each production factor of the service realization will be transferred into $\mathrm{kWh}$ and added to the energy demand of the grinding machine. At the end, the energy demand of one produced part will be compared for both grinding machines.

\section{Acknowledgement}

This research was funded by the German research foundation (DFG) within the IRTG 2057 "Physical Modeling for Virtual Manufacturing Systems and Processes". 


\section{References}

[1] T.W. Zhang, D.A. Dornfeld, Energy Use per Worker-Hour: Evaluating the Contribution of Labor to Manufacturing Energy Use, in: S. Takata, Y. Umeda (Eds.), Advances in Life Cycle Engineering for Sustainable Manufacturing Businesses, Proceedings of the 14th CIRP Conference on Life Cycle Engineering, Waseda University, Tokyo, Japan, June 11th-13th, 2007, pp. 189-193.

[2] J. Fresner, T. Bürki, H.H. Sittel, Ressourceneffizienz in der Produktion, Kosten senken durch Cleaner Production, first ed. Symposion Publishing GmbH, Düsseldorf, 2009.

[3] K. Schischke, E. Hohwieler, R. Feitscher, J. König, S. Kreuschner, P. Wilpert, N.F. Nissen, Energy-Using Product Group Analysis - Lot 5, Machine tools and related machinery, Task 1 Report - Definition, Berlin, Germany, 2012.

[4] M. Dervisopoulos, CO\$TRA - Life Cycle Costs Transparent, Abschlussbericht, Kurzfassung, PTW, Technische Universität Darmstadt, 2008, pp. 26 - 27.

[5] R. Neugebauer, M. Wabner, H. Rentzsch, S. Ihlenfeldt, Structure principles of energy efficient machine tools, In: CIRP Journal of Manufacturing Science and Technology, 2011, No. 4. pp. 136-147.

[6] E. Abele, Energieeffiziente Produktionsmaschinen durch Simulation in der Produktenwicklung, Ergebnisbericht des BMBF Verbundprojektes eSimPro. 2012.

[7] E. Augenstein, J. Nelles, A. Wurm, Energieeffiziente Kühlsysteme für Werkzeugmaschinen Konzept für eine bedarfsorientierte Kühlwasserversorgung, In: wt Werkstattstechnik online, 2012, Vol. 102, No. 5, pp. 306-311.

[8] G. Mert, C. Bohr, S. Waltemode, J.C. Aurich, Increasing the resource efficiency of machine tools by life cycle oriented services, Procedia CIRP 15 - Proceedings of the 21 st CIRP Conference on Life Cycle Engineering, 2014, pp. 176-181.

[9] J.C. Aurich, S. Waltemode, Qualität technischer Produkt-Service Systeme, Wt Werkstattstechnik online 102 (2012) 7-8, pp. 508-512.

[10]E. Manzini, C. Vezzoli, Product-Service Systems and Sustainability - Opportunities for sustainable solutions, 2001, booklet, Milan, Italy.

[11] E. Schweitzer, Lebenszyklusmanagement investiver Produkt-Service Systeme, in: J.C. Aurich (Eds.), Produkt-Service Systeme - Gestaltung und Realisierung, Springer-Verlag, Berlin, Heidelberg, 2010.

[12] C. H. Fuchs, Life Cycle Management investiver Produkt-Service Systeme, in: J.C. Aurich (Eds.), Produktionstechnische Berichte aus dem FBK, Band 04/2007, Kaiserslautern: Techn. Univ., 2007. Zugleich Kaiserslautern, Techn. Univ., Diss., 2007.

[13]G. Mert, S. Waltemode, J.C. Aurich, How Services Influence the Energy Efficiency of Machine Tools, A Case Study of a Machine Tool Manufacturer. Procedia CIRP 29 - Proceedings of the 22nd CIRP Conference on Life Cycle Engineering, 2015, pp. 287-292. 